\title{
A New Bovicornia from St. Thomas and Tortola (United States and British Virgin Islands) and Notes on Bovicornia uniformis (Insecta: Collembola: Sminthuridae $)^{1}$
}

\author{
José A. Mari Mutt ${ }^{2}$
}

\begin{abstract}
Bovicornia bidoma n. sp. is described based on specimens from St. Thomas and Tortola (U.S. and British Virgin Islands, respectively). Additional notes are added to the description of $B$. Uniformis Murphy based on type material and both species are compared. Bovicornia is reported for the first time from the Neotropical Region; it was previously known from Africa and the Solomon Islands.
\end{abstract}

\section{INTRODUCTION}

The genus Bovicornia was erected by Delamare Deboutteville in 1947 (3) for the African (Senegal) species B. coronata. The genus was characterized among the Bourletiellinae by the peculiar sexual dimorphism. Males possess a large dorsal protuberance or "horn" medially between the eyes. This "horn" has a characteristic chaetotaxy and in all species, save B. rhinoceros, three "glandular" areas are present on each side of the dorsal protuberance. All these structures are absent in females. In addition, males are smaller. Delamare Deboutteville (4) described in further detail the sexual dimorphism of $B$. coronata, the only species known at the time.

Murphy (7) described Bovicornia uniformis from Gambia and added details to the description of coronata species, also present in Gambia. Massoud and Delamare Deboutteville (5) revised the genus and added two African species: $B$. rhinoceros and $B$. paulani. In the same paper the authors redescribed $B$. coronata based on the type material.

Massoud and Delamare Deboutteville (6) described B. greensladei from the Solomon Islands, the first record of the genus outside Africa, and presented a key to the species. Betsch (1) made a detailed analysis of postembryonic development of sexually dimorphic characters in $B$. greensladei. The same author (2) described the mating behavior of the latter species. This last paper is of particular interest since it presents a preliminary explanation for the biological significance of the sexual dimorphism.

The new species described below was collected in St. Thomas (U. S. Virgin Islands) and Tortola (British Virgin Islands). It represents the

${ }^{1}$ Manuscript submitted to Editorial Board September 12, 1977.

${ }^{2}$ Graduate Student, Department of Entomology, University of Illinois and Illinois Natural History Survey, Urbana, Ill. 61801. 
first record of this genus from the Neotropical Region and adds Bovicornia to the already significant number of collembolan taxa with a holotropical distribution.

All type material is deposited in the collection of the Illinois Natural History Survey with the exception of two paratypes $(\delta, f)$ deposited in the British Museum (Natural History).

RESULTS

BOVICORNIA BIDOMA n. sp.

\section{Male}

Length up to $.52 \mathrm{~mm}$. Body background color light yellow. Distribution of purple pigment upon antennae and head as in Plate I, fig. 1 and Plate II, fig. 6. Body dorsally unpigmented, laterally with two poorly defined bands of purple pigment running length of body. Legs with very diffuse pigment on all segments. Collophore and furcula unpigmented.

General structure of antennae as in figure 6. Fourth antennal segment (Ant. 4) clearly differentiated in two regions: A proximal nonsubdivided portion and an apical part consisting of six subsegments. Proximal four subsegments very well developed, beadlike. Ant. 2 bears distally a pair of spines (fig. 6). Length of antenna/length of head ( measured along a median line $)=2.4: 1$.

Head chaetotaxy as in figure 1. Minute setae on center of dorsal "horn" vary in number from 10-12. "Glandular" areas are dome shaped and placed in a pit (fig. 2).

Claw structure as in figure 10. Three clavate tenent hairs present. Tibiotarsi bear on inner margin many spinelike setae similar to setae present in other species of the genus. Dental chaetotaxy as in figure 12. Mucro as in figure 11. Bifid setae absent from anal segment.

\section{Female}

Length up to $.70 \mathrm{~mm}$, all females larger than males. Distribution of pigment throughout antennae, head, and body, very diffuse so a pattern can not be described. Legs, collophore, and furcula unpigmented.

Structure of antennae as in figure 7. Ant. 4 composed of two distinct areas but subsegments of the distal portion are less well developed (figs. 6 and 7). Ants. 2 and 3 devoid of spines. Length antenna/length head $=1 \cdot 6: 1$. Head chaetotaxy as in figure 3 .

Abd. 6 with one bifid seta medially on the dorsal valve. Anal appendage consists of a pair of large apically smooth setae (fig. 9). Dental chaetotaxy and mucronal structure as in male. 


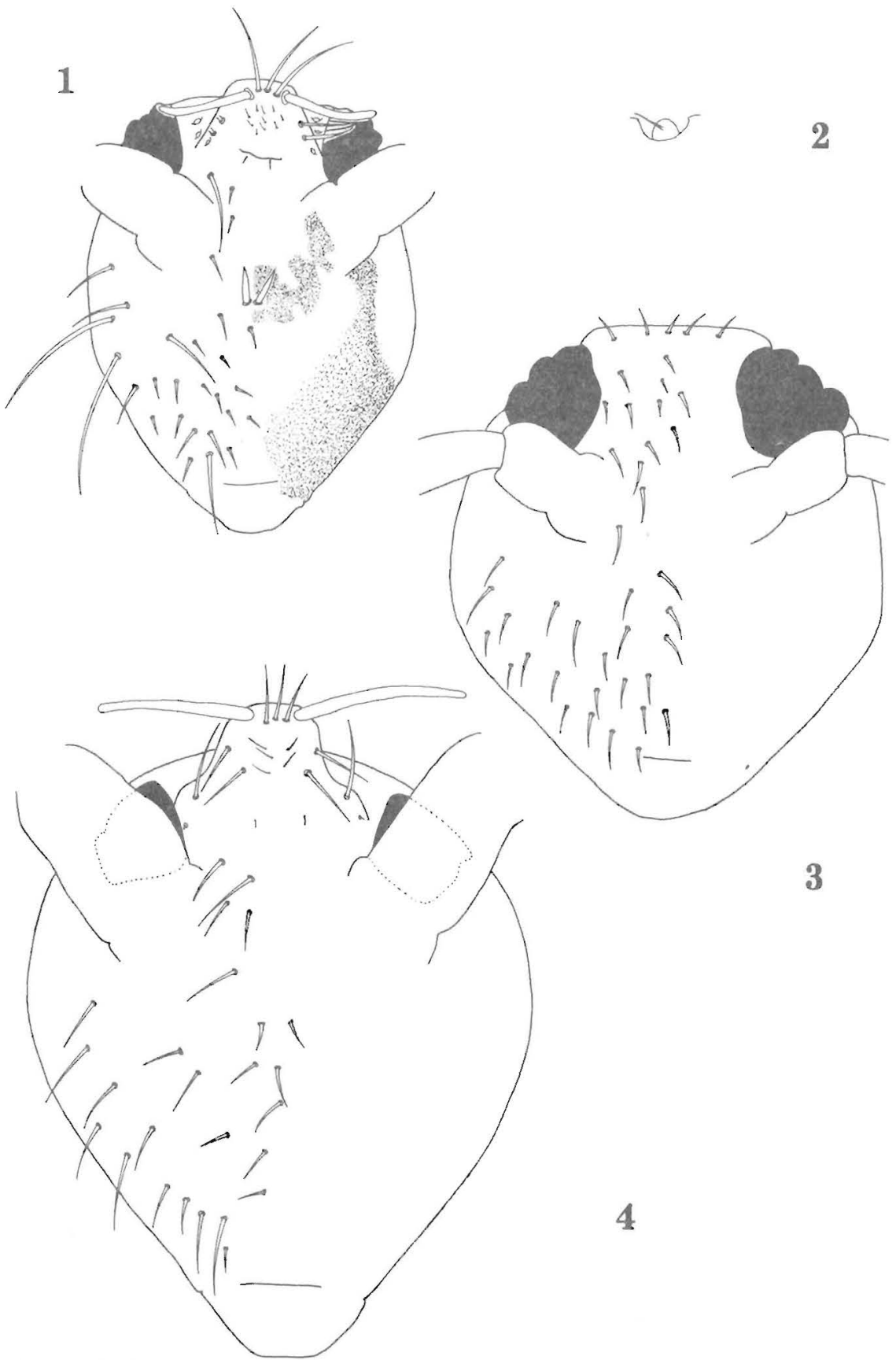

Plate I-(Figs. 1,3-4 drawn to same scale to show size difference). 1. Bovicornia bidoma-Male head chaetotaxy and distribution of purple pigment. Setae shown only on one side. 2. B. bidoma-One of the "glandular" areas on the side of the cephalic protuberance. 3. B. bidoma-Female head chaetotaxy. 4. Bovicornia uniformis-Male head chaetotaxy. 


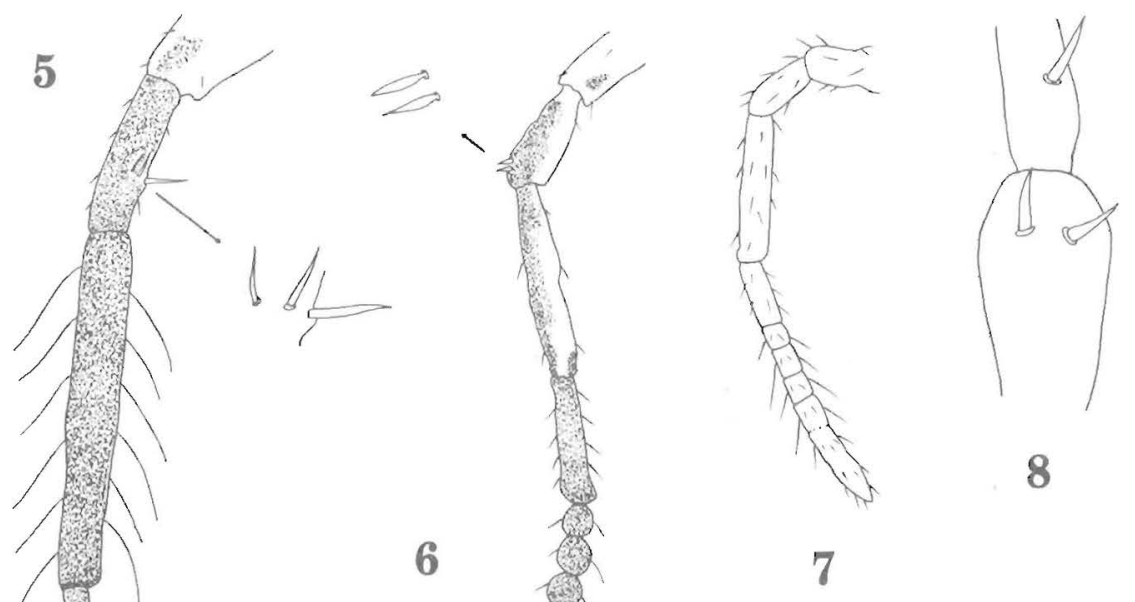

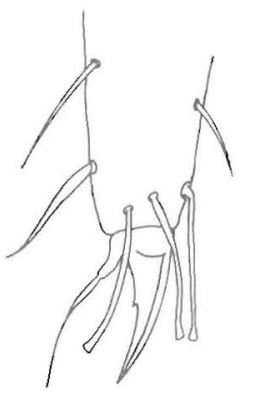

10

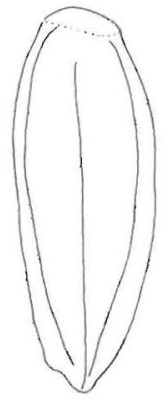

11

Plate II-(Figs. 5-7 drawn to same scale), 5. B. uniformis-Antenna of male. 6. B. bidoma-Antenna of male. 7. B. bidoma-Antenna of female. 8. B. uniformis-Apical portion of Ant. 2 and proximal part of Ant. 3 showing position and shape of spines. 9. B. bidoma-Female anal appendage. 10. B. bidoma-Claw structure of metathoracic leg. 11. B. bidoma-Dorsal view of mucro. 12. B. bidoma-Dorsal view of dental chaetotaxy. 


\section{Diagnosis}

The new species is morphologically closest to Bovicornia uniformis Murphy. Males of both species can be separated on account of size (.75 $\mathrm{mm}$ in uniformis vs. $.52 \mathrm{~mm}$ in bidoma), ratio of length antenna/ length head (3.5:1 in uniformis vs. 2.4:1 in bidoma), various features of head chaetotaxy (figs. 1 and 4), and antennal structure (figs. 5 and 6).

Females can be distinguished on the basis of size $(1.1 \mathrm{~mm}$ in uniformis vs. $.70 \mathrm{~mm}$ in bidoma), absence of spines on Ants. 2-3 in bidoma, and presence of a single bifid seta upon the anal segment of the new species. Bovicornia bidoma may be separated from the other members of the genus by several characters summarized in the key to the species presented by Massoud and Delamare Deboutteville (6).

\section{Material Examined}

British Virgin Islands, Tortola, road to town, July 9, 1958, beating vegetation, M. W. Sanderson, col., Holotype (o), allotype, and 9 paratypes $(50,4$ \%). U.S. Virgin Islands, St. Thomas, Crown Mt., July 7, 1958, beating and sweeping vegetation, M. W. Sanderson, col., 1 paratype (ठ).

\section{NOTES ON BOVICORNIA UNIFORMIS MURPHY 1960}

Through the kindness of Mr. P. N. Lawrence of the British Museum (Natural History), two paratypes of this species were studied. Figure 8 presents the apical portion of Ant. 2 and the basal part of Ant. 3 of the female paratype. The spines present upon this segment are much more conspicuous than may be gathered from Murphy's figure.

Figure 4 presents the head chaetotaxy of the male paratype. A comparison of this figure with figure 1 reveals the many differences between uniformis and bidoma, the most conspicuous of which are the presence of a pair of spines near the middle of the head in bidoma and the relative length of the setae present upon the dorsal "horn".

Figure 5 shows the antennal structure of the male paratype. Compare with figure 6 and note the size and shape of the spines on Ant. 2 and the shape of the subsegments of Ant. 4.

\section{Material Examined}

Gambia, Keneba, August 6, 1956. Two paratypes ô-BM 1958-662, qBM 1958-662 G44.

\section{RESUMEN}

Se describe la nueva especie Bovicornia bidoma proveniente de St. Thomas y Tortola (Islas Vírgenes Estadounidenses y Británicas, respectivamente). Además, se añaden notas a la descripción de la especie africana $B$. uniformis Murphy basadas en el estudio de dos paratipos. El género Bovicornia se registra por primera vez de la región neotropical. 


\section{LITERATURE CITED}

1. Betsch, J. M., 1967. Dévelopment des caractères sexuels secondaires chez Bovicornia greensladei Massoud et Delamare Deboutteville, Rev. Ecol. Biol. Sol., 4(2): 299301.

2. —, 1974. Contribution à l'étude de la reproduction chez les Bourletiellinae (Collemboles Symphypléones), Pedobiol., 14: 179-81.

3. Delamare Deboutteville, C., 1947. Collemboles nouveaux du Sénégal, contribution à la connaisance des Bourletiellini C. B., Bull. Soc. Ent. France, 52(7): 103-7.

4. - - 1951. Caractères sexuels secondaires curieux chez un Collembole symphypléone du Sénégal (Bovicornia coronata Delamare), Conf. Int. Afr. Occ., Bissau, 3(2): 239-44.

5. Massoud, Z., and Delamare Deboutteville, C., 1964. Révision du genre Bovicornia (Collembole Symphypléone), Rev. Ecol. Biol. Sol., 1(3): 519-32.

6. — - and — 1967. Description d'une nouvelle espèce du genre Bovicornia Delamare Debouteville 1947 (Collemboles, Symphypléones) et clef de determination des espèces du genre, J. Nat. Hist., 1: 69-74.

7. Murphy, P. H., 1960. Collembola Symphypleona from the Gambia, with a note on the biogeography of some characteristic savanna forms, Proc. Zool. Soc. London, 134(4): 557-94. 